\title{
Experimental and numerical studies of heat and mass transfer in low-temperature heat accumulator with phase transformations of accumulating material
}

\author{
Valery Gorobets ${ }^{1}$, Ievgen Antypov ${ }^{1}$, Viktor Trokhaniak ${ }^{1}$, and Yurii Bohdan ${ }^{2, *}$ \\ ${ }^{1}$ Heat and Power Engineering Department, Education and Research Institute of Energetics, Automation and Energy Efficiency, \\ National University of Life and Environmental Sciences of Ukraine, Heroyiv Oborony st., 15, Kyiv, 03041, Ukraine \\ ${ }^{2}$ Ships Power Plant Operation Department, Marine Engineering Faculty, Kherson State Maritime Academy, Ushakova \\ avenue, 20, Kherson, 73000, Ukraine
}

\begin{abstract}
Accumulation of thermal energy is produced with the aim of storing at certain times, when there is an overabundance of this energy and its further use in other periods of time when there is a deficit thermal energy. Thermal energy storage may be carried out under heating of any material (water, solid materials etc.) or by using the phase or chemical transformation of the material (melting and crystallization processes, direct and reverse chemical reaction). Thermal accumulators with phase or chemical transformations are allowed to concentrate a large amount of energy in a relatively small volume of accumulating material. In this paper an experimental study and numerical modeling of heat and mass transfer in the heat accumulator during phase transformations of the accumulating material are presented. The experimental plant consists of a chamber filled with paraffin. In experimental studies, the changes of the temperature distribution in heat accumulating material and tube bundles have investigated. Numerical simulation of melting and solidification of heat accumulating material during the heated and cooled of tube bundles were performed. As the results of research, the basic laws of melting and crystallization processes in heat accumulator during phase transformations of heat accumulating material were determined.
\end{abstract}

\section{Introduction}

Analysis of different methods of heat accumulation showed that the most promising type of heat accumulators are heat accumulators of periodic action with phase or chemical transformations of accumulation material [1-3]. Accumulators of this type give an opportunity to provide a high density of accumulated energy per unit of mass and a stable temperature of the coolant at the exit from the heat accumulator. The works [1-14] provide detailed information on the research of heat and mass transfer processes that occur during the phase transformations of the accumulation material. From the analysis of these studies it can be concluded that it is necessary to intensify the processes of heat and mass transfer with "charge" and "discharge" of accumulators and to reduce losses in storage of thermal energy in such accumulators [4-9]. Given the complexity of processes in heat-storage material for such devices, it is necessary to conduct a theoretical and experimental investigations of heat and mass transfer processes in order to optimally locate heat sources in the accumulative material. Such issues are insufficiently studied and require further research [10-14]. In particular, the processes of heat and mass transfer during phase transformations of accumulation material around several horizontally placed cylindrical heat sources are insufficiently investigated.

\section{Analysis and modelling}

On the basis of the analysis of the structures of existing accumulation devices using a package of COMSOL Multiphysics 3.5a a new axonometric model of the heatstorage phase of the phase transition was proposed and developed [15]. We assume that the coolant enters the accumulator and moves along the system of heating pipes, giving or absorbing at the same time the thermal energy that is accumulated or taken away from the accumulation material. As a heat-accumulating material T3 paraffin with a phase transition temperature $\mathrm{T}_{\mathrm{f}}=54 \div 56{ }^{\circ} \mathrm{C}$ was selected.

In the numerical study of these processes, we consider that: 1) the accumulator case is insulated and thermal losses in the environment are absent; 2) the initial temperature throughout the volume of the accumulation material is the same; 3 ) the temperature of the surface of cylindrical heat sources is based on the condition of the thermal balance between the heat received by the heat accumulation material and transferred to the material from heat sources. At the

\footnotetext{
* Corresponding author: bohdanyurii09@ gmail.com
} 
boundary of the phase separation, heat is taken into account, which is absorbed (released) during melting (crystallization) of the accumulation material.

The mathematical model of heat and mass transfer processes in phase transformations of the accumulation material includes the Navier-Stokes equation and the convective heat transfer equation.

$$
\left.\left.\begin{array}{c}
\frac{\partial \rho w_{x}}{\partial \tau}+w_{x} \frac{\partial \rho w_{x}}{\partial x}+w_{y} \frac{\partial \rho w_{x}}{\partial y}=-\frac{\partial p}{\partial x}+\rho g_{x}+\frac{\partial}{\partial x}\left(\mu \frac{\partial w_{x}}{\partial x}\right)+\frac{\partial}{\partial y}\left(\mu \frac{\partial w_{x}}{\partial y}\right), \\
\frac{\partial \rho w_{y}}{\partial \tau}+w_{x} \frac{\partial \rho w_{y}}{\partial x}+w_{y} \frac{\partial \rho w_{y}}{\partial y}=-\frac{\partial p}{\partial y}+\rho g_{y}+\frac{\partial}{\partial x}\left(\mu \frac{\partial w_{y}}{\partial x}\right)+\frac{\partial}{\partial y}\left(\mu \frac{\partial w_{y}}{\partial y}\right)
\end{array}\right\}\right) \begin{gathered}
\frac{\partial \rho}{\partial \tau}+\frac{\partial \rho w_{x}}{\partial x}+\frac{\partial \rho w_{y}}{\partial y}=0 \\
\frac{\partial T}{\partial \tau}+w_{x} \frac{\partial T}{\partial x}+w_{y} \frac{\partial T}{\partial y}=\frac{1}{\rho c_{p}} \frac{\partial}{\partial x}\left(\lambda \frac{\partial T}{\partial x}\right)+\frac{1}{\rho c_{p}} \frac{\partial}{\partial y}\left(\lambda \frac{\partial T}{\partial y}\right) \pm Q_{s}(x, y)
\end{gathered}
$$

In this case, the initial and boundary conditions have the form:

- at the initial moment of time:

$$
T(x, y, \tau=0)=T_{0},
$$

- on the surface of the case:

$$
\left.\frac{d T}{d n}\right|_{s, c}=0
$$

- on the surface of cylindrical heat sources:

$$
T_{s}(x, y)=T_{s, t},
$$

In carrying out numerical calculations of heat transfer in the region of the solid phase of the accumulating material, the equation (3) was used, in which it was assumed that $\mathrm{w}_{\mathrm{x}}=0, \mathrm{w}_{\mathrm{y}}=0$ and the convective elements were absent.

To test the validity of numerical simulation results, a test module (Figure 1) is developed that is made of steel which it is filled the solid accumulative material. This module consist of a horizontally oriented container (housing) in the form of a parallelepiped with height $\mathrm{H}=240 \mathrm{~mm}$, length $\mathrm{L}=500 \mathrm{~mm}$ and width $\mathrm{W}=300 \mathrm{~mm}$. To ensure a uniform accumulation of heat in an array of accumulation material, a tube bundle with a chess or corridor arrangement consisting of 8 steel tubes $(\mathrm{d}=21.3 \times 2.8 \mathrm{~mm})$ located horizontally parallel to the lower wall of the module casing with a relative radius around the heat sources, which is not exceeds $\mathrm{R} \leq 40 \mathrm{~mm}$. We assume that the operating time of the apparatus is $\tau \approx 28800 \mathrm{~s}$ ( 8 hours).

The mass of the accumulative material (paraffin) in the working chamber is $\mathrm{M}_{\mathrm{hm}}=26.1 \mathrm{~kg}$. The thermophysical properties of the accumulative material were determined by the results of laboratory tests, and the properties of the coolant (water) - based on known table values.

The following parameters were chosen for the investigated factors of influence during the accumulation process: temperature and velocity of heat carrier. As parameters of optimization were selected: coefficient of useful use of mass or accumulated material and the degree of heating of material for the lower levels in volume of accumulator.

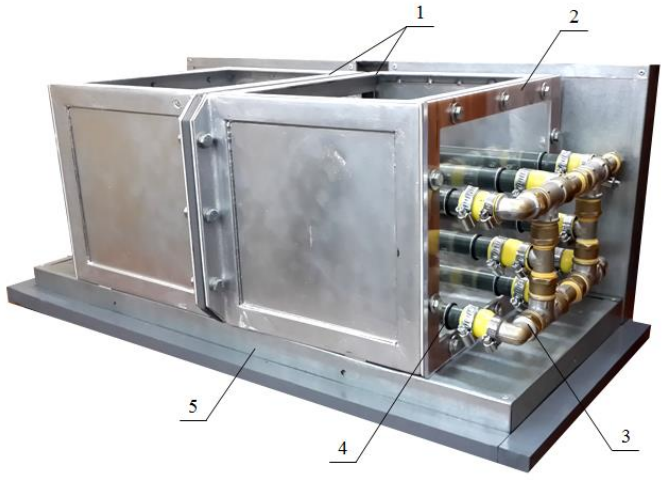

Fig. 1. Appearance of the experimental module: 1 - collapsible case; 2 - face cap; 3 - distribution collector; 4 - tube bundle; 5 - thermal insulation panel.

\section{Results and discussions}

As a result of the numerical simulation (Figure 2a, b) and the experimental studies (Figure 2c, d) of heat and mass transfer processes during phase transformations of the accumulation material around several cylindrical heat sources were found the existence of three melting stages of the heat-accumulating material. In the first stage of melting, the main mechanism of heat transfer is conductive heat transfer. In the second stage of melting, the convective heat transfer is dominant, which is accompanied by intense melting of the accumulation material. The third stage of melting is characterized by overheating of the molten mass of the material with slow melting of the solid mass of the material located in the bottom of the container.

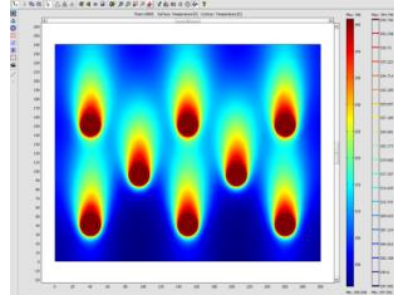

a

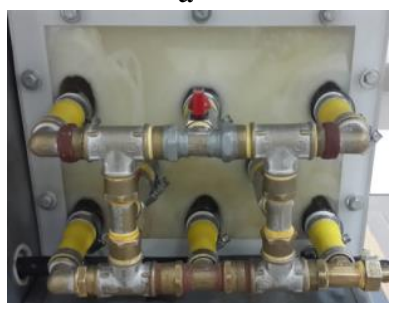

c

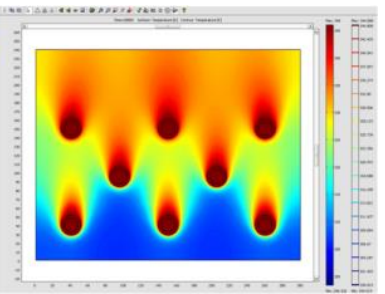

b

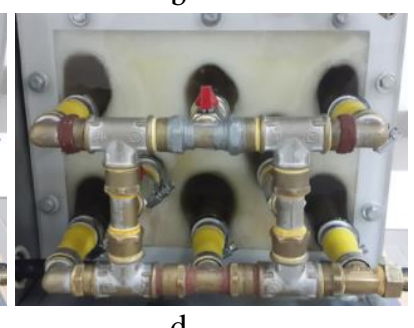

d
Fig. 2. The temperature fields ( $a, b$ - numerical simulation) and the change of the melting profiles (c, d - experimental research) in the system "solid - melt" in the cross section of accumulation material for heat accumulator at the different moments of time: a, c - 30 min; b, d - 180 min.

On the showed Figure 2a,b present temperature fields that has the same scale of the color map with the temperature range from 295 to $350 \mathrm{~K}$ with step $5 \mathrm{~K}$.

On the basis of analysis of the performed researches it was found that for the second phase of melting, the 
maximum value of the mass increase of the molten substance per unit time is characteristicfor the second phase of melting. The third phase is characterized by a slower growth of the mass of the melt in the lower part of the working volume, where there is the appearance of zones of low melting point of the accumulation material, hereinafter referred to as "stagnant zones", the temperature of which is $10-12 \%$ lower than in the region of intense circulation fluid flows (see Fig. 3). In this case, a large amount of heat is spent on overheating of the molten material volume, which is located on the top of the heat accumulator. The duration of such "overheating" is about $25 \%$ of the total time when heat accumulator is in "charge" mode.

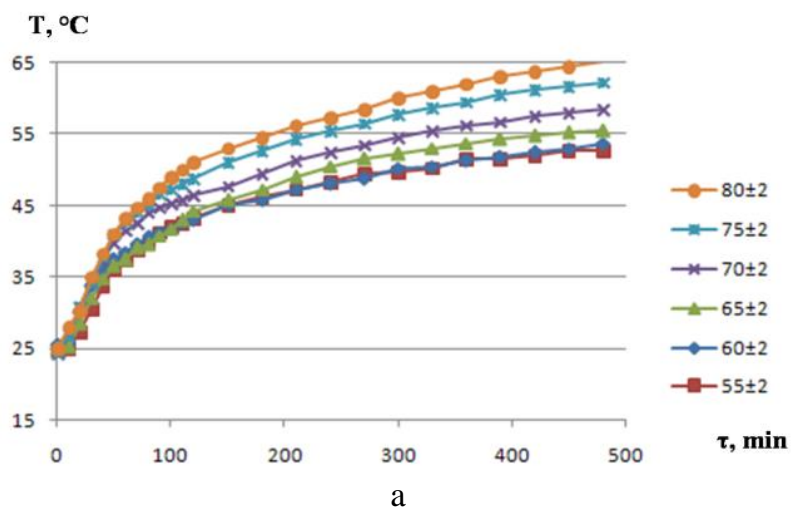

T, ${ }^{\circ} \mathbf{C}$

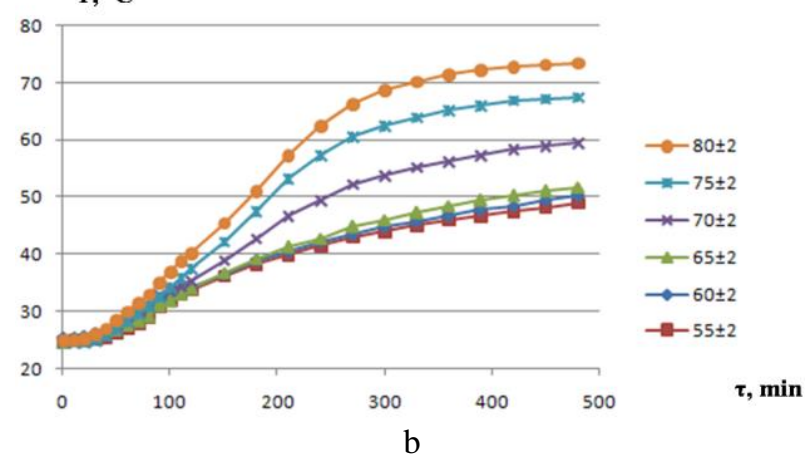

Fig. 3. Dependence of the temperature in volume of the accumulative material on time at different values of the temperature of the coolant at the inlet: a - in the "stagnant zones"; $b$ - in the melt of the material.

The individual curves in Figure 3 showed the dependence of temperature of volume of accumulating material on time for different temperatures of inlet coolant in range from 55 to $80^{\circ} \mathrm{C}$ with step $5{ }^{\circ} \mathrm{C}$.

In order to maximize the heating of the accumulative material in the lower areas of the container and to determine the optimal distances between adjacent cylindrical heat sources and the bottom of accumulator, a series of model calculations was conducted. In the process of numerical computing the dimensions and geometry of the location of heat sources in the volume of accumulation material is changed. As a result of numerical calculations, an optimal distance (radius) between heat sources was found, which made it possible to reduce the weight and dimensions of heat accumulator and increase its heat accumulation capacity. For different geometric parameters of the cylindrical heat transfer surface, the value of the optimal distance (radius) $R$ between the heat sourcesthe bottom of accumulatoris obtained.

The analysis of the results of numerical simulation gives the following conclusion: placing the lower row of heating elements from the bottom and lateral walls of the accumulator case should be carried out at a distance not exceeding the value of the optimal distance (radius) $R$, which are shown in Table 1.

Table 1. The value of the optimal distance (radius) between the heat sources and the bottom and lateral walls in the volume of the accumulative material, depending on the diameter of the cylindrical sources

\begin{tabular}{|c|c|c|c|c|c|c|}
\hline \multirow{2}{*}{ Parameter } & \multicolumn{6}{|c|}{ Nominal diameter (inches) } \\
\cline { 2 - 7 } & $1 / 2$ & $3 / 4$ & 1 & $1 \frac{1}{4}$ & $1 \frac{1}{2}$ & 2 \\
\hline $\begin{array}{c}\text { External } \\
\text { diameter of heat } \\
\text { exchangers (mm) }\end{array}$ & 21,25 & 26,75 & 33,50 & 42,25 & 48,00 & 60,00 \\
\hline $\begin{array}{c}\text { Optimal radius } \\
\mathrm{R}(\mathrm{mm})\end{array}$ & 30,00 & 35,00 & 45,00 & 57,00 & 70,00 & 85,00 \\
\hline
\end{tabular}

Experimental studies have confirmed the results of numerical modeling on which the necessity of placing the bottom row of heating elements on the bottom and lateral walls of the battery casing, the axial distance which is equal to the optimal radius $\mathrm{R}$. It is established that the excess of this value by $20 \%$ leads to a decrease in the mass of accumulation material by $7 \%$. Choosing the optimal distance between the cylindrical sources and the bottom wall of case leads to minimization of stagnant zones during the accumulation of thermal energy and reducing the time of "charging" the heat accumulator by $15-20 \%$.

A comparison of the results of numerical simulation (curves 1.3 in Figure 4) and experimental data (curves 2.4) for melting processes (curves 1.2 - "charge" of the accumulator) and crystallization (curves 3.4 "discharge" of the accumulator) is carried out. The analysis of the obtained results is showed that the difference between the numerical and experimental data for the temperatures during melting (curves 1 and 2) of the heat-accumulating material does not exceed $3 \%$, and during its crystallization - no more than $5 \%$ (curves 3 and 4 in Figure 4).

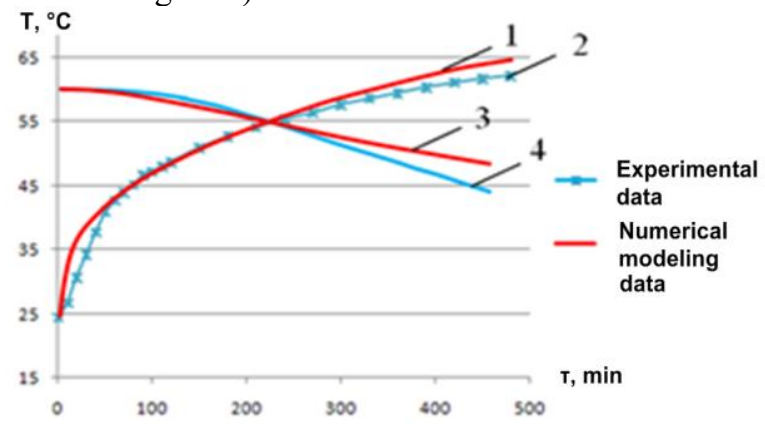

Fig. 4. Comparison of the results of numerical simulation $(1,3)$ with experimental data $(2,4)$ of the thermal characteristics of the heat-accumulating material in the process of "charging" and "discharging" the heat accumulator 


\section{Conclusions}

1. Analysis of the obtained temperature fields and melting profiles of the accumulation material in the system "solid-melt" for different moments of time revealed the presence of three melting phases.

2. In the first phase, the heat transfer from the heat source to the phase separation by the main transfer mechanism is conductive heat transfer with uniform melting of the heat accumulating material along the perimeter of the cylindrical heat source.

3 . In the second phase, the convective heat transfer is dominant. This period is characterized by the presence of intense convective flows, which leads to an increase in the efficiency of the melting process and to increase the melting speed of the material placed above the heat sources.

4. The third phase of melting is characterized by overheating of liquid mass of accumulation material, slowing melting processes in the lower part of the battery and reducing the growth of the mass of the melt. The duration of the "overheating" stage is about $25 \%$ of the total time of work for heat accumulator in the "charge" mode. In the lower part of the working volume there are "stagnant zones", the temperature of which is $12 \%$ lower than in the area of intense circulation of fluid.

5. As a result of the numerical calculations of the processes of heat and mass transfer in the heat accumulator of phase transition on the basis of paraffin, an optimal distance (radius) $\mathrm{R}$ between cylindrical heat sources is established in which the heat accumulation capacity of the accumulator will be maximal. Experimental investigations have confirmed that the bottom row of heating elements in the accumulating material should be located at a distance not exceeding the optimal radius $\mathrm{R}$, which minimizes the number of stagnant zones and reduces the time of "charging" the accumulator by $15-20 \%$.

\section{Acknowledgments}

Publication is based on the research provided by the grant support of the State Fund for Fundamental Research of Ukraine, the Ministry of Education and Science of Ukraine (project N F64/11-2016).

\section{References}

1. R. Velraja, R. Seeniraja, B. Hafnerb, C. Faberb, K. Schwarzerb, Sol. Energy, 65(3), pp. 171-180 (1999).

2. Q. Zhang, Y. Huo, Z. Rao, Science Bulletin, 61(5), pp. 391-400 (2016).

3. Iu. Nasieka, V. Strelchuk, V. Naseka, Yu. Stubrov, S. Dudnik, V. Gritsina, O. Opalev, K. Koshevoy, V. Strel'nitskij, V. Tkach, M. Boyko, I. Antypov, J. Cryst. Growth, 491, pp. 103-110 (2018).

4. J. Pereira da Cunha, P. Eames, Appl. Energ., 177, pp. 227-238 (2016).
5. L. Liu, D. Su, Y. Tang, G. Fang, Renew. Sust. Energ. Rev., 62, pp. 305-316 (2016).

6. L. Fan, J. Khodadadi, Renew. Sust. Energ. Rev., 15(1), pp. 24-46 (2011).

7. F. Agyenima, N. Hewitta, P. Eamesb, M. Smyth, Renew. Sust. Energ. Rev., 14(2), pp. 615-628 (2010).

8. A. Regin, S. Solanki, J. Saini, Renew. Energ., 31, pp. 2025-2041 (2006).

9. S. Jegadheeswaran, D. Pohekar, Renew. Sust. Energ. Rev., 13(9), pp. 2225-2244 (2009).

10. S. Kuboth, A. König-Haagen, D. Brüggemann, Energies, 10, 274 (2017).

11. Y. Huo, Z. Rao, Int. J. Heat Mass Tran., 86, pp. 197-206 (2015).

12. S. Kalaiselvam, M. Veerappan, A. Arul, S. Iniyan, Int. J. Therm. Sci., 47(7), pp. 858-874 (2008).

13. A. Sharma, V. Tyagi, R. Chen, D. Buddhi, Renew. Sust. Energ. Rev., 13, pp. 318-345 (2009).

14. V.G. Gorobets, V.V. Treputnev, Teplofizika Vysokikh Temperatur, 33 (4), pp. 588-593 (1995).

15. I. Antypov, Scientific herald of the National University of Life and Environmental Sciences of Ukraine, 224, pp. 208-213 (2015). 